\title{
Cholangiocarcinoma Secondary to Primary Sclerosing Cholangitis in Explanted Livers: A Single-Center Study in the South of Iran
}

\author{
Bita Geramizadeh, ${ }^{1,2,{ }^{*}}$ Roshanak Ghavvas, ${ }^{2}$ Kurosh Kazemi, ${ }^{3}$ Alireza Shamsaeefar, ${ }^{3}$ Saman \\ Nikeghbalian, ${ }^{3}$ and Seyed-Ali Malekhosseini ${ }^{3}$ \\ ${ }^{1}$ Department of Pathology, Shiraz University of Medical Sciences, Shiraz, IR Iran \\ ${ }^{2}$ Transplant Research Center, Shiraz University of Medical Sciences, Shiraz, IR Iran \\ ${ }^{3}$ Department of Hepatobiliary and Liver Transplant Surgery, Shiraz University of Medical Sciences, Shiraz, IR Iran \\ ${ }^{*}$ Corresponding Author: Bita Geramizadeh, Department of Pathology, Transplant Research Center, Shiraz University of Medical Sciences, Shiraz, IR Iran. Tel: +98-7136473954, \\ E-mail:geramib@gmail.com
}

Received 2015 October 6; Revised 2015 November 24; Accepted 2015 November 28.

\begin{abstract}
Background: Primary sclerosing cholangitis (PSC) is a chronic disease, characterized by chronic inflammation and fibrosis of bile duct epithelial cells. This is a significant contributory factor to the development of malignancy, most commonly cholangiocarcinoma (CCA), which is the second most common malignant liver tumor.

Objectives: For the first time in Iran, we intend to describe our experience with cases of PSC, with and without CCA, in explanted livers, and compare our results with those found in other areas of the world.

Patients and Methods: The study population comprised 181 individuals with a diagnosis of PSC who had undergone liver transplantation in the main liver transplant center of Iran, the largest center of hepatobiliary surgery in the south of that country, over a 3-year period between 2012 and 2014. All explanted livers, with and without CCA, were evaluated.

Results: Of the 181 patients, 16 were found to have CCA, two of whom had been diagnosed after pathologic study of the explanted livers. Therefore it appeared that $8.8 \%$ of the patients with PSC in our center had developed CCA before liver transplantation.

Conclusions: A comparison of our results with those obtained from other centers in both Western and Asian countries (which reported CCA in $3.6 \%-36.5 \%$ of patients with PSC), shows that the incidence of CCA in the patients we studied is intermediate.

Keywords: Primary Sclerosing Cholangitis, Cholangiocarcinoma, Liver Transplantation, Cirrhosis
\end{abstract}

\section{Background}

Primary sclerosing cholangitis (PSC) is a chronic cholestatic liver disease. It is characterized by progressive inflammation and fibrosis of the intra and extrahepatic bile ducts, which leads to progressive cholestasis, hepatic injury, and eventually liver cirrhosis (1). People with PSC are at high risk of developing cholangiocarcinoma (CCA), the reported incidence of which varies across different areas of the world (2). As there is no effective medical treatment for PSC, and liver transplantation (LT) results have been excellent, LT remains the optimum treatment choice for PSC patients with end-stage liver disease $(3,4)$.

\section{Objectives}

In this brief report, we describe our experience evaluating the incidence of CCA in people with PSC who have undergone LT. Their explanted livers were studied over a 3 year period in the largest liver transplant center in Iran, and the results were compared to the incidence of CCA secondary to PSC that has been found in different areas of the world. To the best of our knowledge, such a study has not previously been performed in Iran.

\section{Patients and Methods}

The cases of 181 people with a diagnosis of PSC or CCA who had undergone LT in the liver transplant unit of Namazi Hospital, Shiraz, Iran, between 2012 and 2014 were extracted from the pathology file and evaluated. Those patients with a histopathologically confirmed diagnosis of PSC and CCA were also identified.

\section{Results}

During the 3-year study period, of the 181 cases of PSC, 16 were found to have CCA and 165 were found to be free of malignancy, following a thorough examination of the explanted livers (Figure 1). Two of the 16 CCA cases were of very small CCA ( $<0.5 \mathrm{~cm}$ in diameter), in which LT had been performed without a pre-transplant diagnosis of CCA; the diagnosis was made after pathologic examination of the explanted liver (Figure 2). In the remaining 14 CCA cases, this malignancy had been diagnosed pre-transplant (Figure 3). Table 1 shows the characteristics and demographic findings of the PSC patients with and without CCA.

Copyright ( 2015, Kowsar Corp. This is an open-access article distributed under the terms of the Creative Commons Attribution-NonCommercial 4.0 International License (http://creativecommons.org/licenses/by-nc/4.0/) which permits copy and redistribute the material just in noncommercial usages, provided the original work is properly cited. 


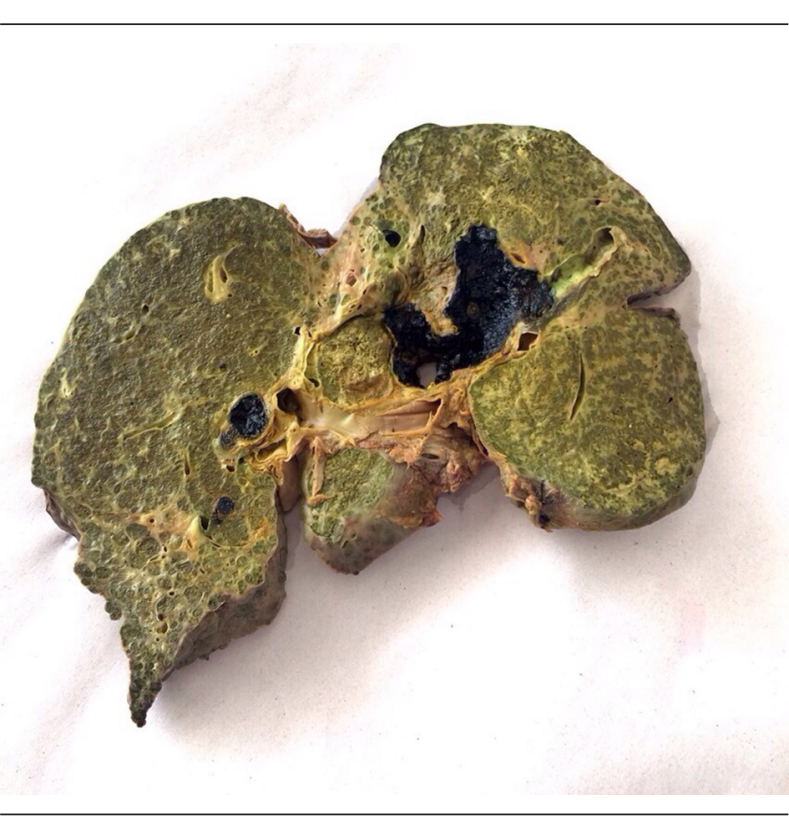

Figure 1. A Section From an Explanted Liver With Primary Sclerosing Cholangitis

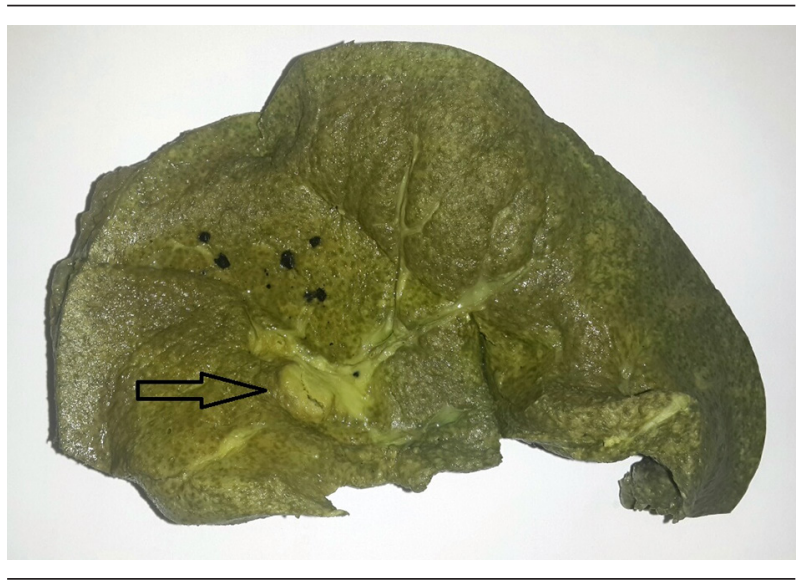

Figure 2. A Section From an Explanted Liver With Primary Sclerosing Cholangitis and Cholangiocarcinoma (arrow) Diagnosed After Liver Transplantation

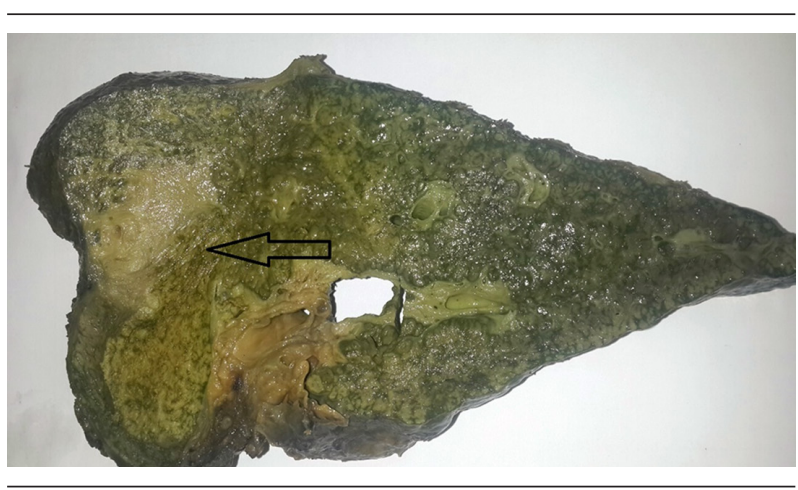

Figure 3. A Section From an Explanted Liver With Primary Sclerosing Cholangitis and Cholangiocarcinoma (arrow) Diagnosed Before Liver Transplantation
Table 1. The Characteristics and Demographic Findings of the Individuals With Primary Sclerosing Cholangitis, With and Without Cholangiocarcinoma

\begin{tabular}{lccc}
\hline & Number $^{\mathbf{a}}$ & Age $^{\mathbf{b}}$ & F/M \\
\hline PSC without CCA & $165(91.2)$ & $35.98 \pm 12.4$ & $1 / 1.5$ \\
PSC with CCA & $16(8.8)$ & $48.8 \pm 9.2$ & $1 / 3$ \\
\hline
\end{tabular}

Abbreviations: CCA, Cholangiocarcinoma; PSC, Primary sclerosing cholangitis.

${ }^{\mathrm{a}}$ Data are presented as No. (\%)

${ }^{\mathrm{b}}$ Data are presented as mean \pm SD.

\section{Discussion}

PSC is a chronic cholestatic disease, characterized by inflammation and fibrosis of bile ducts, which leads to biliary strictures, stasis, and liver cirrhosis. The worst complication of PSC is the development of CCA, for which there is no effective non-surgical therapy, and which is considered to be a malignancy with a poor prognosis (5). The mean age of our PSC patients who did not have CCA was 35.18 \pm 11.7 , which was significantly lower than the mean age for patients with concomitant PSC and CCA. It has been reported that development of CCA in patients with PSC usually occurs when these individuals are aged in their 40s. CCA without PSC develops later in life, when people are aged in their 70s (6). In the largest study conducted in Iran, in which 283 people with CCA were followed-up between 2001 and 2004, the mean age of the patients was $59.7 \pm 14.4$ (2). In our study, the male to female ratio in the 16 CCA patients was 1.3. Mohammad-Alizadeh et al. estimated that this ratio was 1.7 (180 males and 103 females) in 283 Iranian CCA patients (4). Therefore, in people from Iran, CCA is more common in males, which is partly because PSC (the major risk factor for CCA) affects men more than women (7). As has been mentioned, the prevalence of CCA in PSC patients in our center was $8.8 \%$, with 16 patients of the total number of 181 having concomitant PSC and CCA. It is worth noting that two patients (12.5\%) were diagnosed as having CCA only following pathologic study of the explanted liver. The incidence rate of CCA in PSC patients in our center was largely similar to that found in a Swedish study, in which, of 45 cases of PSC, four (8.9\%) developed CCA during a 10-year follow-up between1975 and 1984 (8). The lowest prevalence has been reported in Norway (9), with four CCA patients out of 75 PSC cases (5.3\%), and the highest prevalence has been reported in Australia, where CCA was diagnosed in four patients out of 11 with PSC at the time of transplantation, and recurrence of tumor was observed in two patients (10).

Among studies from Europe, The Netherlands (5), Germany (11), and Italy (12) have reported a $10.3 \%, 12 \%$, and $6 \%$ incidence risk, respectively, of CCA in people with PSC. Studies from several US states, showed different association risks and reported prevalence rates of between 7 and 11\% (13-18). Studies from Asia reported a lower prevalence rate of CCA in PSC, with 3.6\% shown in a Japanese study (7), and 5.3\% found in Turkey (19). Table 2 shows the percentage of people with PSC who developed CCA during the years of follow-up or at the time of liver transplantation. In some studies, significant recurrence during follow-up was reported, even after liver transplantation (11). 
Geramizadeh B et al.

Table 2. The Incidence of Cholangiocarcinoma in Different Parts of the World in Comparison to Our Center

\begin{tabular}{lcc}
\hline Author & Country & Incidence of CCA in PSC Patients $^{\mathbf{a}}$ \\
\hline Ponsioen et al.(5) & The Netherlands & 10.3 \\
Tanaka et al.(7) & Japan & 3.65 \\
\hline Broome et al.(8) & Sweden & 8.9 \\
\hline Schrumpf et al.(9) & Norway & 5.3 \\
\hline Strasser et al.(10) & Australia & 36.5 \\
\hline Lutz et al.(11) & Germany & 12 \\
\hline Mosconi et al.(12) & Italy & 6 \\
\hline Multiple studies (13-18) & USA & $7-11$ \\
\hline Ataseven et al.(19) & Turkey & 5.3 \\
\hline The current study & Iran & 8.8 \\
\hline
\end{tabular}

Abbreviations: CCA, Cholangiocarcinoma; PSC, Primary sclerosing cholangitis.

${ }^{\mathrm{a}}$ Data are presented as No. (\%)

The incidence rate of CCA secondary to PSC in Namazi Hospital of Shiraz, the largest referral center in the south of Iran, was estimated to be $8.8 \%$, which is intermediate in comparison with other Western and Asian countries. Although we cannot explain the reason for this difference, it appears to be an ethnic and genetic issue. Further prospective studies are necessary to identify the reasons for this difference in incidence.

\section{Acknowledgments}

This research has been based on research protocol No: 5380 from Shiraz University of Medical Sciences Research, Iran.

\section{References}

1. LaRusso NF, Shneider BL, Black D, Gores GJ, James SP, Doo E, et al. Primary sclerosing cholangitis: summary of a workshop. Hepatology. 2006;44(3):746-64. doi: 10.1002/hep.21337. [PubMed: 16941705]

2. Chalasani N, Baluyut A, Ismail A, Zaman A, Sood G, Ghalib R, et al. Cholangiocarcinoma in patients with primary sclerosing cholangitis: a multicenter case-control study. Hepatology. 2000;31(1):7-11. doi: 10.1002/hep.510310103. [PubMed:10613720]

3. Jn S-Y, Kim JS, Yu E. Primary sclerosing cholangitis-A report of two liver explants. Korean J Pathol. 2002;36:420-4.

4. Mohammad-Alizadeh AH, Ghobakhlou M, Mohaghegh Salimi $\mathrm{H}$, Zali MR. Cholangiocarcinoma: An eight-year experience in a tertiary center of Iran. Asian Pacific J Cancer Prev. 2012;13(5381-4).

5. Ponsioen CY, Vrouenraets SM, Prawirodirdjo W, Rajaram R, Rauws EA, Mulder CJ, et al. Natural history of primary sclerosing cholangitis and prognostic value of cholangiography in a Dutch population. Gut. 2002;51(4):562-6. [PubMed: 12235081]

6. Baskin-Bey ES, Moreno Luna LE, Gores GJ. Diagnosis of cholangiocarcinoma in patients with PSC: a sight on cytology. J Hepatol. 2006;45(4):476-9. doi: 10.1016/j.jhep.2006.07.006. [PubMed: 16901574]

7. Tanaka A, Takamori Y, Toda G, Ohnishi S, Takikawa H. Outcome and prognostic factors of 391 Japanese patients with pri- mary sclerosing cholangitis. Liver Int. 2008;28(7):983-9. doi: 10.1111/j.1478-3231.2008.01726.x. [PubMed: 18397233]

8. Broome U, Olsson R, Loof L, Bodemar G, Hultcrantz R, Danielsson A, et al. Natural history and prognostic factors in 305 Swedish patients with primary sclerosing cholangitis. Gut. 1996;38(4):610-5. [PubMed: 8707097]

9. Schrumpf E, Boberg KM, Karlsen TH. Primary sclerosing cholangitis: the Norwegian experience. Scand $J$ Gastroenterol. 2015;50:781-96. [PubMed:25866138]

10. Strasser S, Sheil AG, Gallagher ND, Waugh R, McCaughan GW. Liver transplantation for primary sclerosing cholangitis versus primary biliary cirrhosis: a comparison of complications and outcome. J Gastroenterol Hepatol. 1993;8(3):238-43. [PubMed: 8518394]

11. Lutz H, Trautwein C, Tischendorf JW. Primary sclerosing cholangitis: diagnosis and treatment. Dtsch Arztebl Int. 2013;110(5152):867-74. doi:10.3238/arztebl.2013.0867. [PubMed: 24529302]

12. Mosconi S, Beretta GD, Labianca R, Zampino MG, Gatta G, Heinemann V. Cholangiocarcinoma. Crit Rev Oncol Hematol. 2009;69(3):259-70. doi: 10.1016/j.critrevonc.2008.09.008. [PubMed:18977670]

13. Singh S, Talwalkar JA. Primary sclerosing cholangitis: diagnosis, prognosis, and management. Clin Gastroenterol Hepatol. 2013;11(8):898-907. doi: 10.1016/j.cgh.2013.02.016. [PubMed: 23454027]

14. Angulo P, Lindor KD. Primary sclerosing cholangitis. Hepatology. 1999;30(1):325-32. doi: 10.1002/hep.510300101. [PubMed: 10385674]

15. Singal AK, Stanca CM, Clark V, Dixon L, Levy C, Odin JA, et al. Natural history of small duct primary sclerosing cholangitis: a case series with review of the literature. Hepatol Int. 2011;5(3):808-13. doi:10.1007/s12072-011-9260-4. [PubMed:21484124]

16. Silveria MG, Lindor KD. Primary sclerosing cholangitis. . Can J Gastroenterol. 2008;22(689):98.

17. Razumilava N, Gores GJ, Lindor KD. Cancer surveillance in patients with primary sclerosing cholangitis. Hepatology. 2011;54(5):1842-52. doi:10.1002/hep.24570. [PubMed:21793028]

18. Rosen CB, Nagorney DM, Wiesner RH, Coffey Jr RJ, LaRusso NF. Cholangiocarcinoma complicating primary sclerosing cholangitis. Ann Surg. 1991;213(1):21-5. [PubMed: 1845927]

19. Ataseren H, Paralak E, Yuksel I, Basel O, Ertugrul I, Sasmaz N. Primary sclerosing cholangitis in Turkish patients. Characteristic features and prognosis. Hepatobil Pancreat Dis Int. 2009;8:312-5. 